\title{
HABEAS CORPUS: VARIANTES Y SUBTIPOS EN EL DERECHO NACIONAL ARGENTINO
}

\author{
Néstor Pedro Sagürés \\ Profesor de Derecho Político \\ Facultad de Derecho y Ciencias Sociales de Rosario \\ (Universidad Catolica Argentina)

I. Introducción. El habeas corpus y la Constitución Nacional. 2. Subupos de habeas corpus. 3. Habeas corpus reparador, o tradicional. 4. Habeas corpus preventivo. 5. Habeas corpus restringido. 6. Habeas corpus de pronto despacho. 7. Habeas corpus por mora en in traslación. 8. Habeas corpus correctivo. 9. Habeas corpus modificativo. 10. Conclusiones.

1. Introducción. El habeás corpus y la Constitución Nacional. En Argentina, la legislación sobre habeas corpus es múltiple. Por un lado, está el habeas corpus (con sus diversas variantes) propio del or den nacional; y por el otro, veintidós órdenes más de habeas corpus, uno por cada Provincia.

La forma de legislar el habeas corpus es diversa. En el ámbito nacional (y en varias provincias) está tratado en el código de procedimientos en lo penal: es la solución tradicional y más antigua. En el ámbito provincial, ha sido legislado algunas veces conjuntamente con la acción de amparo, que es un instituto semejante al mandato de seguridad brasileño (asi, ley 2257 de Catamarca; ley 5180 de Salta); o incluso mediante una ley especial (Provincia de San Luis, ley 3665, por ejemplo). Como el recurso de habeas corpus es un tema de derecho procesal constitucional1, cualquiera de las dos últimas opciones citadas es preferible a la primera: el habeas corpus, en efecto, poco tiene que hacer en un código procesal criminal, ya que no se propone castigar delitos, sino salvaguardar garantías constitucionales.

'Cłr. N. P. Sagǘés, "Derecho Procesal Constitucional y jurisdicción constitucional", en La Ley, 1981-C-865. 
Precisamente sobre ese punto, la doctrina juridica discute si el habeas corpus está o no en la Constitución Nacional. En su art. 18, ella dispone que "Nadie puede ser... arrestado sino en virtud de orden escrita de autoridad competente"; y la discusión existente gira en torno a esta pregunta: ¿incluye o no la Constitución en esa frase al instituto del habeas corpus?

Un sector de la doctrina ha pensado que hay un vacio en el texto constitucional de 1853 , hoy vigente, laguna que se procuró cubrir con la reforma constitucional de 1949 (dejada sin efecto en 1956). Entre quienes así piensan, han estado Lazcano, Casiello y Ramella. Otro grupo de autores (Estrada, Joaquín V. González), entiende que el habeas corpus podría estar en la Constitución, pero que de todos modos ha sido necesario que el legislador ordinario complementase al recurso, a través de la legislación común, para tornarlo funcional. Por último, un tercer núcleo de publicistas considera que el habeas corpus está implicitamente insertado en el texto de la Constitución, y que es directamente operativo, aunque no haya ley ordinaria que lo reglamente (Sánchez Viamonte, Humberto Quiroga Lavié) ${ }^{2}$.

La discusión es importante, porque si se concluye que el habeas corpus (en el orden nacional) no figura expresa o implícitamente en la Constitución, quedaría a merced del legislador ordinario ponerlo o no en práctica. A nuestro entender, el habeas corpus está sobreentendido en la Constitución Nacional, no solamente por la cláusula constitucional ya transcripta (nadie puede ser arrestado...) sino también porque Alberdi (autor del proyecto de ley suprema en el que inmediatamente se inspira la Constitución de 1853), indicó que el instituto del estado de sitio incluido en la Constitución, equivalía a la decisión de "suspensión del habeas corpus" propia del derecho norteamericano. Luego, el habeas corpus era tácitamente previsto por el constituyente, ya que se programó - por otro mecanismo constitucional- su limitación, en supuestos excepcionales.

Por último, conviene recordar que para la Corte Suprema de Justicia de la Nación, el habeas corpus nace no solamente de la ley, puesto que lo reputa establecido también por la Constitución (Colección de "Fallos", 300-457; 301-1047; 302-772, etc.). La opinión del alto tribunal puede poner fin, en este punto, a la duda sobre si el habeas

sobre el tema, mi "Habeas Corpus. Régimen constitucional y procesal en la Nación y provincias". (Buenos Aires, 1981), ed. La Ley, 73 ss. 
corpus está o no "constitucionalizado" en el derecho nacional argentino.

2. Subtipos de habeas corpus. Vamos a limitarnos a contemplar al habeas corpus, preferentemente en el ordenamiento nacional. $X$ en esa esfera, bueno es advertir que no existe un tipo de habeas corpus, sino al menos siete. Ellos derivan algunas veces de la ley formal, pero en otras ocasiones son producto de la jurisprudencia, que ha respondido - con acierto o no- a determinados problemas no contemplados por el legislador ordinario.

En concreto, los principales subtipos de habeas corpus que pueden detectarse son:

a) el habeas corpus reparador, tradictonal o clásico;

b) el habeas corpus preventivo;

c) el habeas corpus restringido;

d) el habeas corpus de pronto despacho;

e) el habeas corpus por mora en la traslacion;

f) el habeas corpus correctivo;

g) el habeas corpus modificativo.

Presentaremos acto seguido a tales acciones.

3. Habeas corpus reparador, o tradicional. Este habeas corpus supone un "arresto", "prisión" o "detención" ya consumado, dispuesto sin orden escrita o por autoridad incompetente, $y$ al que se intenta poner fin mediante el breve trámite del habeas corpus. Está previsto legalmente por el art. 617 del código de procedimientos en lo penal de la Nación.

Inieresa averiguar cómo ha extendido la jurisprudencia el concepto de "arresto" a ciertas situaciones singulares. Por ejemplo, ha abierto al liabeas corpus para cuestionar la incorporación de ciudadanos al servicio militar (caso "Santodomingo E.": "Fallos", 208-78); la retención de personal contratado por la Armada mediante contratos inválidos ("La Ley", 11-696); la "reclusión de menores" dispuesta incorrectamente por un Defenșor Oficial (Jurisprudencia Argentina, 1947-r. 409); la internación en nosocomios de personas contra su voluntad, sin orden de juez comperente y sin juicio de insania (Digesto Jurídico ¿a Ley, t, vil p. 1208); la expulsión de extranjeros; la negativa de admisión de personas a Argentina (Corte Suprema de Justicia de la Na- 
ción, 164.290; Jurisprudencia Argentina, 1942-I-601) el "alojamiento" compulsivo de extranjeros en trance de ingresar al pais ("El Derecho", 57-695), etc.

Ultimamente el habeas corpus ha penetrado en el discutido tema de la judiciabilidad de las "cuestiones políticas" (political questions). Por ejemplo, en el caso "Zamorano" y en el primer caso "Timerman", la Corte Suprema de Justicia de la Nación estableció para los casos de detención de personas por el Poder Ejecutivo Nacional en virtud del estado de sitio, que el Poder Judicial debía realizar un examen de razonabilidad entre las causas que habían motivado la declaración del estado de sitio, y las razones alegadas por el Poder Ejecutivo Nacional para detener en concreto a una persona. Dicho de otro modo, al Poder Judicial en general, y a la Corte Suprema de Justicia en especial, actuando como tribunal de garantías constitucionales, le corresponde controlar la aplicación que haga el Poder Ejecutivo de sus facultades, durante dicho estado de sitio ("Jurisprudencia Argentina", 1978-1-240-/2 y 1978-Iv-121).

En el segundo caso "Timerman", la Corte Suprema de Justicia de la Nación, también mediante un procedimiento de habeas corpus, contemplo otra "cuestión poH́tica", como era la "internación" de un ciudadano, dispuesta por un "Acta de Responsabilidad Institucional". La Corte indicó que las dos únicas maneras constitucionales de privar de su libertad a una persona, eran el estado de sitio o por proceso legal; y que la mencionada "internación" (que, de hecho, equivalía a una sanción) no encajaba en ninguna de aquellas dos hipótesis, motivo por el que era inconstitucional. ("La Ley", 1979-D-146). Indirectamente, a través de un habeas corpus, la Corte reputó entonces inconstitucional un Acta institucional dictada por la Junta Militar, que había invocado el ejercicio del poder constituyente.

También se ha aplicado el habeas corpus reparador para remediar la negativa del Poder Ejecutivo del ejercicio del "derecho de opción" de detenidos por el estado de sitio, a fin de poder salir del territorio argentino.

Interesa asimismo advertir, por último, que cuando se interpone un habeas corpus a fin de analizar la legalidad de un arresto, el tribunal respectivo se limita, por lo común, a un estudio formal, sobre si existe orden escrita de autoridad competente. En casos especiales (arrestos a disposición del Poder Ejecutivo, por aplicación del "estado 
de sitio" v. gr.), el tribunal evalúa además, en alguna medida, el contenido de la orden de detención (juzgando, por ejemplo, la razonabilidad de la medida privativa de la libertad).

4. Habeas corpus preventivo. ¿Es necesario esperar que una persona esté arrestada, para que prospere un recurso de habeas corpus? La doctrina antigua de la Corte Suprema de Justicia de la Nación (caso "Lino de la Torre", v.gr.), asi lo indicaba: si no habia "preso" o "detenido", no era viable el habeas corpus.

Sin embargo, la mayor parte de los constitucionalistas apoyó la doctrina permisiva de los habeas corpus preventivos: si la Constitución indica que nadie puede ser arrestado sin orden escrita de autoridad competente, ¿por qué esperar el arresto, para garantizar la libertad ambulatoria? En concreto, el art. 617 del código de procedimientos criminales de la Nación autoriza el habeas corpus "contra toda orden o procedimiento de un funcionario público tendiente a restringir sin derecho la libertad de una persona..." aunque el arresto no se haya efectivizado.

La jurisprudencia, en cuanto el habeas corpus preventivo, requiere que la amenaza a la libertad sea cierta, y no meramente presuntiva. Por eso, se demanda la demostración "de la positiva existencia de la amenaza o restricción de la libertad" ("La Ley", 56-293; 60-253).

Actualmente, el instituto del habeas corpus preventivo es usual en la experiencia tribunalicia argentina.

5. Habeas corpus restringido. Una tendencia jurisprudencial ha abierto el habeas corpus para remediar no situaciones extintivas de la libertad, sino restricciones menores al "ius movendi et ambulandi". Aludimos aqui a molestias, perturbaciones, limitaciones al acceso a determinados lugares (universidades, fuentes de trabajo, etc.).

En un principio, ciertos tribunales retacearon este tipo de habeas corpus. Por ejemplo, se dijo que no procedía un habeas corpus con. tra la vigilancia de la policía de una casa, en cuanto no atacara la libertad de una persona (Cámara Criminal de la Capital Federal, "Fallos", 47-148, 59-393, etc.). Tampoco, si un particular era citado a efectos de fotografiarlo $e$ incorporar la fotografia al "álbum de malvivientes" (Jurisprudencia Argentina, t. 25-1975, p. 110); pero 
posteriormente ha admitido al instituto, por ejemplo si la actitud policial de vigilancia de una casa es infundada 3 .

El habeas corpus "restringido" es un instituto primero de raiz jurisprudencial, y es un oportuno despliegue del art. 18 de la Constitución Nacional. Si entendemos que el habeas corpus combate "toda especie de traba puesta a la libertad del hombre" (Story), obvio es que debe tutelar tanto la destrucción absoluta de esa libertad ambulatoria (el arresto), como las lesiones menores (molestias y demás perturbaciones a la libertad corporal).

6. Habeas corpus de pronto despacho. Esta variante del habeas corpus ha sido ocasionalmente utilizada para instar trámites administrativos, frente a la negligencia u omisión de funcionarios públicos.

Un caso interesante, al respecto, se suscita en la causa "Lonaiz Jorge M.", resuelto por el juzgado nacional en lo criminal de instrucción Nọ 13, de Buenos Aires. Un detenido, con condena firme, peticionó cumplidos los términos del caso la concesión del benefício denominado de "libertad condicional". Para ello, era necesario contar con un informe de la Dirección Nacional del Servicio Pentenciario Federal, quien demoraba hacerlo. Después de dos meses, el interesado articuló un recurso de habeas corpus, a fin de obtener tal informe. El tribunal aludido hizo lugar a la acción, intimando al mencionado servicio penitenciario a que se expidiera en el plazo de diez dias ("El Derecho", 52-400).

En verdad, este tipo de habeas corpus es discutible, porque en el hay detenido con orden escrita de autoridad competente (la sentencia del juez de la causa). Para concluir con la demora administrativa, lo más oportuno, seguramente, hubiese sido promover una acción de amparo por mora de la administración, y no un habeas corpus.

De todos modos, interesa mencionar a esa incipiente variante del habeas corpus, como producto jurisprudencial destinado a remediar situaciones de omjsión - bastante frecuentes- de la administración pública, cuando ellas lesionan la libertad física.

7. Habeas corpus por mora en la traslación. Un caso singular se presenta cuando una persona está detenida en determinado lugar, a disposición de un juez que reside en otra jurisdicción (nacional o ex.

v. Malagarriga C. y Sasso S. A., "Procedimiento penal argentino". (Buenos Aires, 1910), ed. Lajouane, t. ui 239/240. 
tranjera). ¿Qué ocurre si el juez requirente no manifiesta en un pla2o razonable que está interesado en la captura del detenido, o aunque diga eso, no envia la comisión para concretar el traslado del preso?

lnicialmente la Corte Suprema de Justicia de la Nación (caso "José de la Cruz Castillo", por ejemplo), juzgó que no era procedente en tales supuestos un habeas corpus ("Falios", 229-34). La conclusión tenía sus fundamentos, porque en tales casos había orden escrita de detención, y autoridad competente que la habia ordenado. Sin embargo, algunos tribunales empezaron a abrir el habeas corpus al que estamos haciendo referencia. Así, la Cámara Federal de la Capital, sala penal, en los autos "González Aguilera Luis", señaló que un detenido a disposición de un juez extranjero no podía esperar, indefinidamente, a "que el pais extranjero requirente, sin plazo establecido, decida proseguir con los trámites de Ia extradición" (Jurisprudencia Argentina, 1964-v/81).

Un evento posterior, el dictado de Ja ley 20.711 , vino a cambiar el panorama, dando sustento legal al habeas corpus aludido. Esa norma establece plazos concretos para que el tribunal que reclama a un preso confirme su interés en la detención, y venga en la búsqueda del mismo. Vencidos tales plazos, corresponde disponer la libertad del preso, aún de oficio; pero lo usual, en diversas jurisdicciones, es que se plantee un habeas corpus para disponer tal liberación.

E1 "habeas corpus por mora en la traslación" no tiene su origen en la Constitución, sino en el derecho pretoriano y en la legislación ordinaria.

8. Habeas corpus correctivo. Este es un habeas corpus especial, programado (especialmente por la jurisprudencia) para concluir con el trato indebido que se dé a un detenido, v.gr. porque el lugar dẹ detención no es el adecuado, o porque se lo somete a vejámenes, o porque el sistema carcelario no es correcto.

Un caso muy frecuente, en pro de este habeas corpus, es el de los detenidos a disposición del Poder Ejecutivo en virtud del estado de sitio, que en algunas ocasiones se los ha sometido a un régimen de detención establecido para los presos de máxima peligrosidad (ley 19.683). La Cámara Federal de la Capital, Sala Penal, en el caso "Sivak" dispuso hacer lugar a este habeas corpus (que llamamos "correc. ivo", porque corrige una situación de arresto que no corresponde), 
al decir que el aludido sistema de "máxima peligrosidad", aplicado a un arrestado a disposición del Poder Ejecutivo, importaba en la práctica sufrir un arresto de modo equivalente a una pena de derecho criminal, lo que no era constitucionalmente aceptable (Jurisprudencia Argentina, t. 18-1973, p. 439). En otras palabras, el arresto en razón del estado de sitio en nada afecta la honorabilidad del detenido; y por eso, éste no puede estar sometido al mismo régimen de un procesado o condenado (voto del Dr. Ríos Centeno, en autos "Manuel Rodríguez y otro", Cámara Federal de La Plata, en "La Ley" 138-777).

La corrección jurídica del habeas corpus "correctivo" es discutible. Debe observarse que en los casos aludidos, había orden escrita de detención emanada de autoridad competente. Y si un preso a disposición de un juez recibe un trato inadecuado, lo habitual es que sea el juez de su causa, quien tiene bajo su custodia al procesado o condenado, quien deba remediar en el respectivo expediente penal lia irregularidad que se denuncie. A su vez, si un detenido a disposición del Poder Ejecutivo por el "estado de sitio" es sometido a un trato humillante o inapropiado, en rigor de verdad no se está afectando su libertad física y ambulatoria (puesto que está privado totalmente de ella), sino otro derecho humano (el de dignidad de trato), que en el derecho argentino encontraría una solución mejor por la vía de la acción de amparo (art. 1, ley 16.986).

Débese tener en cuenta que, en el derecho argentino, la tutela rápida de los derechos constitucionales se consigue mediante el aludido juicio de amparo (ley 16.986, principalmente), excepto el derecho a la libertad física, protegido a través del habeas corpus.

9. Habeas corpus modificativo. En el caso "Moya", resuelto por la Corte Suprema de Justicia de la Nación el 15/5/81, emergió una nueva alternativa de habeas corpus, que conviene reseñar.

Moya había sido detenido seis años atrás, tanto a disposición del Poder Ejecutivo Nacional, por el estado de sitio, como a disposición de la Justicia, por ciertos procesos. En el ámbito judicial fue sobreseído, razón por la que sólo quedó detenido en razón del estado de sitio.

En tal condición, Moya peticionó ejercer el derecho que le otorga el art. 23 de la Constitución Nacional ("derecho de opción", o de salir del territorio argentino), que le fue reiteradamente denegado por 
el Poder Ejecutivo. A la postre, planteó un habeas corpus peticionando dos cosas: a) que se le otorgara por vía judicial dicho "derecho de opción"; b) en su defecto, que se le modificara el régimen de detención común derivado del "estado de sitio", por otro más benigno, que se llama "de libertad vigilada".

La Corte Suprema de Justicia de la Nación juzgó que atento el tiempo transcurrido y habiendo sido Moya sobreseido en sede penal, la denegatoria sistemática por parte del Poder Ejecutivo del citado "derecho de opción", implicaba indirectamente una condena a prisión por tiempo determinado, lo que es incompatible con las facultades constitucionales del Poder Ejecutivo, quien no puede aplicar penas ni ejercer funciones judiciales (arts, 23 y 95). En resumen, el Poder Ejecutivo habia ejercido sus atribuciones (en tal caso) irrazonablemente, al denegar reiteradamente el derecho de opción, razón por la que dispuso autorizar la salida del país de Moya dentro del plazo de quince días hábiles, excepto si el Poder Ejecutivo modificaba la forma de arresto, transformándolo en "libertad vigilada".

En los autos "Moya", la Corte Suprema de Justicia de la Nación implementó el habeas cotpus para "modificar' un tipo de detención (el ordinario) por otro más leve (la situación de "libertad vigilada"). En tal caso, el habeas corpus sirvió no para obtener la libertad fisica, sino para stavizar el tipo de arresto. En tal sentido, este habeas corpus "modificativo" guarda paralelismo con el habeas corpus "correctivo" que se expuso en el parágrafo 8 . La diferencia entre ambos podría mantenerse, sin embargo, señalando que el habeas corpus "modificativo" se propone la transformación de un régimen de detención por otro; en tanto que el "correctivo" reclama que el tipo de detención dispuesto, sea cumplido sin atentar contra la salud o dignidad del preso.

10. Conclusiones. Un repaso de los distintos subtipos de habeas corpus ensayados en el orden nacional argentino, permite arribar a cicrtas conclusiones.

La primera de ellas indica que la jurisprudencia ha desenvuelto - desarrollado, en lugar de restringir, las figuras del habeas corpus que emergen tácitamente de la Constitución, o dinectamente del código procesal en lo penal. Esto importa una actitud positiva de los tribunales, ya que los miembros del Poder Judicial, por lo común. 
han afirmado así el derecho constitucional al "ius movendi et ambulandi".

La segunda observación es que tal desarrollo jurisprudencial del habeas corpus se ha acrecentado durante los gobiernos "de facto". La Corte Suprema de Justicia de la Nación, con acierto, ha dicho que en tales periodos, cuando el Poder Ejecutivo asume facultades legislativas, al Poder Judicial le corresponde acentuar sus funciones de control y de tribunal de garantías constitucionales. Tal doctrina es naturalmente encomiable, aunque no siempre haya podido concretarse debidamente ${ }^{4}$.

Por último, el reexamen de las distintas clases de habeas corpus permite esbozar una clasificación provisoria de ellos. Así, en primer término, se encuentran los habeas corpus en sentido propio, que operan cuando no hay orden escrita de autoridad competente, y se proponen obtener la libertad del detenido, o terminar con amenazas o lesiones menores a esa libertad física. Aquí pueden situarse al habeas corpus reparador, al preventivo y al restringido.

En otro campo distinto, es factible mencionar los habeas corpus en sentido impropio, que actúan aunque haya orden escrita de detención emanada de autoridad competente. Ellos son el habeas corpus de pronto despacho, por mora en la traslación, correctivo y modificativo.

El futuro de estos habeas corpus "en sentido impropio" no es bien claro. Algunos de ellos quizá serán captados por la denominada "acción de amparo", mientras que otros, probablemente, ingresarán en forma definitiva al catálogo de los habeas corpus. Lo importante, claro está, no es dónde esté ubicado un instituto, sino que sea realmente operativo y eficaz.

4Sobre las dificultades del Poder Judicial para obtener respuestas y da. tos completos por parte del Poder Ejecutivo, en la sustanciación de habeas corpus, cabe mencionar los casos "Capello Ernesto G." (La Ley, 1978-A373) y sobre todo, "Pérez de Smith Ana M. y otros". (La Ley, 1979-A-430), por ejemplo. 